\title{
Cultura e território da imigração polonesa no município de Áurea/RS
}

\author{
The culture and territory of polish immigration in Áurea, Rio Grande do Sul
}

- Brazil

\section{Thaimon da Silva Socoloski ${ }^{1}$ Eduardo Schiavone Cardoso ${ }^{2}$}

$\begin{array}{ll}\text { Palavras-chave } & \text { Resumo } \\ \text { Códigos culturais } & \text { A imigração europeia para o sul do Brasil constituiu-se como um dos principais } \\ \text { Território } & \text { fluxos migratórios que integraram o processo de colonização e desenvolvimento } \\ \text { Polonidade } & \text { agrícola visado pelo estado brasileiro. Neste fluxo migratório, destaca-se o papel } \\ & \text { da imigração polonesa para o Rio Grande do Sul. A presente pesquisa tem como } \\ & \text { foco a colonização e o povoamento do município de Áurea, a partir do ano de } 1911 . \\ & \text { Como objetivo geral, busca-se analisar e discutir a importância deste processo } \\ & \text { migratório nos códigos culturais que se imprimem no cotidiano dos descendentes } \\ & \text { poloneses que residem no município atualmente. Desta forma, analisaram-se os } \\ & \text { seguintes códigos culturais: religião, língua e dialeto, arte, danças, música, } \\ & \text { culinária, arquitetura e vestimentas típicas. Observou-se que, após mais de um } \\ & \text { século de colonização, muitos destes códigos ainda se mantêm vivos nas tradições } \\ & \text { e no cotidiano dos descendentes, expressos principalmente nos ritos religiosos, no } \\ & \text { dialeto e na culinária. Porém, observa-se que o processo de assimilação de novas } \\ & \text { culturas, impressas na cultura brasileira, vem se tornando cada vez mais latente } \\ & \text { e vem substituindo tradições que sobreviveram e ainda sobrevivem nas gerações } \\ & \text { mais próximas dos imigrantes. Assim, o processo de valorização e perpetuação } \\ & \text { das heranças e memórias dos imigrantes é uma tarefa de suma importância para } \\ & \text { que a história do município de Áurea não seja esquecida. }\end{array}$

\section{Keywords}

Cultural codes

Territory

Polish identity

\begin{abstract}
The European immigration to the south of Brazil became one of the main migratory flows in the colonization process as well as in the agricultural development aimed by the Brazilian state. Considering this migratory flow, the Polish immigration was important to Rio Grande do Sul and, primarily, as the main focus in this study, the colonization of Áurea, starting in 1911. The main purpose is to discuss the importance of this migratory process to the cultural elements which appear in the routine of these Polish descendants who currently live in Áurea. Then, the following cultural codes were analyzed: religion, language and dialect, arts, dance, music, cuisine, architecture and costume. It was possible to observe that for decades and since the new generations, after more than one century of colonization, most of these codes are still alive in the traditions and the descendants' daily habits, their religious ceremonies, the dialect and the cuisine. However, the process of new culture assimilation in Brazil has become more latent and it is replacing the tradition which survived and has been surviving among the generations closer to the immigrants. Finally, the valorization and the perpetuation of the immigrants' heritage and memories have been kept, from generation to generation, and this process is crucial to avoid neither losing nor forgetting the history of Áurea.
\end{abstract}

\footnotetext{
${ }^{1}$ Universidade Federal de Santa Maria, Santa Maria, Rio Grande do Sul, Brasil. thaimon.geo@gmail.com

2 Universidade Federal de Santa Maria, Santa Maria, Rio Grande do Sul, Brasil. educard@smail.ufsm.br
} 


\section{INTRODUÇÃO}

A migração populacional se caracteriza pelo deslocamento de indivíduos em um determinado espaço geográfico, sendo estes fluxos parte de um processo permanente ou temporário de instalação destes sujeitos, sendo motivados por diferentes fatores de atração e/ou expulsão, onde destacam-se os fatores econômicos, religiosos, culturais e naturais entre os principais desencadeadores.

A migração econômica é a que exerce maior influência na população, sendo caracterizada como o deslocamento de contingentes humanos para áreas onde o sistema produtivo concentra uma maior ou melhor oportunidade de trabalho.

No Brasil, coexistiram no processo imigratório duas grandes atividades distintas, sendo elas: a colonização e a imigração. A primeira visava a formação de colônias de estrangeiros que tornassem permanente a ocupação de certas regiões, já a segunda era a atividade de iniciativa particular, cuja finalidade associava-se aos interesses da grande lavoura (WENCZENOVICZ, 2002).

As migrações pelo território brasileiro estão, em grande maioria, associadas a fatores econômicos, desde o tempo da colonização. Nesta esteira migratória, a migração polonesa ganha destaque pela sua contextualização de crise da República da Polônia no final do século XIX e início do século XX, ocasionando a emigração de seus habitantes em busca de melhores condições de vida, que em grande parte ocorreu para o Brasil e demais países da
América (GRITTI, 2004).

A chegada dos imigrantes poloneses a região onde se localiza o município de Áurea/RS se deu no ano de 1911. A colonização do município se inseriu diretamente na política governamentista de desenvolvimento da região Sul do Brasil, com o objetivo de abastecimento do mercado agrícola interno e externo

Assim, constata-se que o surgimento de Áurea, bem como seus processos de desmembramentos e emancipação, passa diretamente pela locação de terras para os imigrantes europeus, principalmente os de origem polonesa. A identidade polonesa se mantém ao longo das décadas, tornando o território aurense em uma "extensão da pátria deixada para trás" no final do século XIX e início do século XX.

A temática de pesquisa sobre a imigração polonesa para o município de Áurea se justifica pela necessidade de contribuir para o entendimento deste processo migratório, que corresponde a cerca de $20 \%$ dos imigrantes que desembarcaram no Rio Grande do Sul.

$\mathrm{O}$ presente trabalho tem como objetivo reconhecer a contribuição dos imigrantes poloneses na organização espacial e cultural do município de Áurea/RS, analisando o processo de desterritorialização e reterritorialização dos imigrantes poloneses no Rio Grande do Sul, apontando a importância da presença dos imigrantes poloneses no processo de desenvolvimento de Áurea/RS, e por fim, caracterizar os códigos culturais poloneses e suas representações no município. 
No que tange aos procedimentos metodológicos, utilizou-se a abordagem qualitativa, a partir da pesquisa exploratória de campo, documental e entrevistas com os moradores. Os códigos culturais analisados foram identificados com base nas observações realizadas no município de Áurea/RS. Desta forma, foram elencados oito diferentes códigos culturais que se manifestam atualmente, sendo eles: religião, língua e dialeto, danças, música, arte, arquitetura, culinária e trajes típicos. A identificação destes códigos foi realizada pela sua manifestação - em maior ou menor grau - no município em questão.

\section{REVISÃO DAS MATRIZES TEÓRICAS.}

A temática cultural vem sendo abordada por várias ciências distintas. $\mathrm{Na}$ geografia, este estudo surge como uma linha de pesquisa que busca explicar as relações humanas e suas implicações no espaço. Debates e discussões em torno deste conceito fizeram com que diversos estudos e conceituações surgissem, aprimorando-o como um dos conceitos-chave para o estudo da relação sociedade/natureza (PICCIN, 2009).

De acordo com Piccin (2009), a abordagem cultural na geografia diz respeito à humanidade como um todo, onde os diferentes grupos interagem e se transformam no decorrer do tempo.

Entende-se aqui a geografia cultural como o estudo das diferentes manifestações culturais, como religião, crenças, rituais, artes, formas de trabalho, ou seja, ideias de um grupo social e de um povo. Assim, a cultura se materializa como a soma de saberes e conhecimentos de um determinado grupo social. Esta soma de saberes, compreendida pela geografia humana e cultural como flutuante, e que se modifica e se adapta aos diferentes meios e contextos, não pode ser considerada como acabada ou imutável, nem como uma cultura homogênea (BRUM NETO, 2007).

Muitas são as formas de se visualizar uma determinada cultura no espaço. É través da compreensão dos códigos culturais que se caracterizam essas transformações culturais, sua cristalização na cultura de um povo, bem como a substituição de hábitos por outros através das adaptações, por diversas forças, de tradições que se transformam ao longo dos tempos.

Para Brum Neto (2007, p. 43),

Os códigos culturais configuram-se como convenções simbólicas partilhadas por uma mesma comunidade social. E, responsável pela sua identificação, salientando a diferença, uma vez que cada grupo cultural é permeado por um sistema simbólico de representação particular, (re)construído no constante processo evolutivo das sociedades. [...] A cultura mediada pelos códigos é representada e materializada no espaço, originando formas típicas, passíveis de reconhecimento pelos demais grupos sociais. Decifrar e interpretar os códigos significa entender a dinâmica da cultura em questão, os valores e crenças que orientam as atitudes e ações. Estas, por sua vez, são repetidas maquinalmente como um padrão orientador comum.

Observa-se, assim, que a partir dos códigos culturais tem-se a identidade cultural. Nesta pesquisa, os diferentes códigos culturais 
identificados demonstram a mutabilidade da cultura, seus símbolos e signos que se perpetuam, se adaptam, e se modificam ao longo do tempo.

A identidade cultural está intimamente ligada ao território onde ela se manifesta. Para Haesbaert (1999, p. 179), “a identidade social é também territorial quando o referente simbólico central para a construção desta identidade parte do ou transpassa o território". Almeida (2008, p. 108) vai ao encontro de tal afirmação, já que para o autor "o território é objeto de operações simbólicas e é nele que os atores projetam suas concepções de mundo".

Corrêa (2012) afirma que as formas simbólicas espaciais são dotadas de sentido político, que são concebidas visando: a) glorificar o passado; b) reconstruir o passado, conferindo-lhe novos significados; c) transmitir valores de um determinado grupo; d) afirmar a identidade de um grupo religioso, étnico, racial, ou social; e e) criar lugares de memória.

Claval (2014) apresenta a identidade cultural como uma ação cristalizada no território, carregando assim uma visão geográfica destes processos. Para o autor, a identidade se apresenta através de marcos e sinais visíveis sobre o terreno: as igrejas nas pequenas cidades, as cruzes ao longo dos caminhos, os minaretes, os cemitérios de geometrias indecisas, cuja presença repetida é sinal de pertencimento, de reconhecimento, de confirmação de identidades.

O território é visto como algo gerador de raízes e de identidade: um grupo não pode ser compreendido sem o seu território, no sentido de que a identidade sociocultural das pessoas estaria inarredavelmente ligada aos atributos do espaço concreto - natureza, patrimônio arquitetônico e paisagem (SOUSA, 1995).

Raffestin (1993) afirma que o território se forma a partir do espaço, sendo este o resultado de uma ação conduzida por um ator sintagmático em qualquer nível. Ao se apropriar de um espaço, concreta ou abstratamente, o ator "territorializa" o espaço.

Assim, o território é aqui compreendido como um construtor de identidade, onde a territorialização e desterritorialização estão carregadas de simbolismos que identificam e caracterizam seus agentes atuantes.

\section{CARACTERIZAÇÃO DA ÁREA DE ESTUDO}

O município de Áurea está localizado no norte do estado do Rio Grande do Sul, pertencente à Mesorregião Noroeste Rio-Grandense. Segundo a classificação climática de KöppenGeiger, o município possui clima subtropical úmido, bioma mata-atlântica e uma altitude média de 587 metros sob o nível do mar, possuindo $158,29 \mathrm{~km}^{2}$ de área.

Segundo dados do Instituto Brasileiro de Geografia e Estatística (IBGE), contidos no Censo Demográfico de 2010, a população do município era de 3.665 pessoas, sendo que 2.128 pessoas viviam na área rural e 1.537 pessoas viviam na área urbana. De acordo com os dados da estimativa populacional fornecidos pelo IBGE no ano de 2019, o município conta atualmente com uma população de 3.554 habitantes (IBGE, 2019). 
A economia do município é essencialmente voltada para atividades rurais, com a produção de grãos, como soja, milho, trigo e feijão. Cabe ressaltar o cultivo e a produção de erva-mate, que visam atender ao mercado local e regional.

Uma das características marcantes da região hoje polarizada por Erechim, sendo este o pólo comercial e cidade mais populosa da região, é a diversidade étnica e cultural de sua população. Isso se evidencia desde a sua fundação. Nos documentos de entrada de imigrantes que correspondem aos anos de 1911 a 1914, encontramos o registro de imigrantes de nacionalidade alemã, austríaca, polonesa, russa, italiana, portuguesa, sueca, holandesa e japonesa (GRITTI, 2004).

\section{ETAPAS MIGRATÓRIAS}

No final do século XIX, a industrialização tomou força nos Estados Unidos, a partir do surgimento de inúmeras fábricas, bem como da expansão de lavouras e de minas de carvão, criando uma alta demanda de trabalhadores para suprir tamanha produção, tal como agricultores, mineiros e operários profissionais (WENCZENOVICZ, 2002).

Por iniciativa de indústrias norteamericanas, desencadeou-se uma intensa campanha com o objetivo de recrutar nos países europeus trabalhadores de diversas profissões com fins de que alavancassem a produção. Em face das boas vantagens ofertadas, e pelo fato de a Europa estar em um período de recessão econômica, grandes contingentes de europeus cruzaram o oceano atlântico emigrando para os Estados Unidos em busca de emprego e melhores condições de vida. Nesta leva de imigrantes, Stawinski (1976) destaca os trabalhadores oriundos de países como Irlanda, Itália, Polônia e Alemanha.

Nesta esteira de migração para a América, anos mais tarde, igual propaganda começa a ser feita para os países da América Latina, de forma que o governo brasileiro adere ao movimento, visando atrair novos braços e novos elementos para suas terras (STAWINSKI, 1976).

Segundo Wenczenovicz (2002), o processo migratório europeu decorreu do excesso de mão de obra nas aldeias e nas vilas europeias, da falta de terras para as novas gerações, da ausência de leis agrárias, bem como da desvalorização do artesanato rural devido à Revolução Industrial.

Posterior a este período de imigração alemã e italiana, em decorrência da proibição do governo alemão de imigrantes virem ao Brasil, o governo brasileiro viu-se obrigado a procurar novas fontes de imigrantes em regiões menos desenvolvidas da Europa. Foi nessa esteira que começou a imigração polonesa para o país (GARDOLINSKI, 1956).

A vinda de europeus era um objetivo do governo brasileiro para atrair imigrantes, visando à ocupação de regiões estratégicas do território, a fim de aumentar a produção de alimentos para abastecimento do mercado interno e para exportação de produtos agrícolas para outros países (STAWINSKI, 
1976).

Gardolinski (1956) divide a imigração polonesa para o Brasil em três diferentes momentos históricos, sendo eles: a $1^{a}$ fase (1869-1871), na qual registrou-se a entrada das primeiras 32 famílias polonesas no Brasil, que foram encaminhadas para a atual cidade de Brusque, em Santa Catarina, então povoada, sobretudo, por imigrantes alemães. A $2^{\mathrm{a}}$ fase (1873-1891), na qual cresce a imigração polonesa para o Estado do Paraná. E a $3^{\text {a }}$ fase (1895-1914), sendo esta a mais significativa em termos quantitativos e históricos, já que houve uma imigração maciça de poloneses para o Brasil após a proclamação da República (1889). O período ficou conhecido como "febre brasileira". Estima-se que, entre os anos de 1890 e 1914, cerca de 96.000 poloneses desembarcaram no Brasil, sendo que o Paraná recebeu aproximadamente 35.000 indivíduos e o Rio Grande do Sul recebeu 32.000 imigrantes.

A chegada dos primeiros imigrantes à região onde hoje se localiza o município de Áurea ocorreu no ano de 1911, sendo estes provindos das regiões de Kalisz, Plock, Varsóvia e arredores, então dominadas pelo Império Russo (WENCZENOVICZ, 2002).

A colonização desta área, assim como as demais áreas do sul do Brasil que receberam levas de imigrantes europeus, tinha como principais objetivos: substituir a mão de obra escrava pela mão de obra livre, num momento em que ocorria a expansão do capitalismo mundial; povoar e colonizar áreas ainda virgens com núcleos de pequenos proprietários agrícolas; bem como estruturar a cadeia produtiva, visando contribuir para o abastecimento interno do país e amenizar o desnível da balança comercial, causado pelo grande peso das importações de alimentos.

No ano de 1908 foi fundada a colônia de Erechim. No ano de 1953, o Distrito de Gaurama se emancipa de Erechim, de modo que Áurea passa a fazer parte do município gauramense. No ano de 1987, juntamente com outras localidades vizinhas que contavam com maciça presença de imigrantes, Áurea alcança sua emancipação, para receber o título simbólico de "Capital Brasileira dos Poloneses" em 1997, perpetuando assim suas raízes e ligações com a cultura polonesa.

\section{POLONIDADE - IDENTIDADE CULTURAL E CÓDIGOS CULTURAIS}

A polonidade se caracteriza como a culturalização polonesa passada pelos imigrantes para seus descendentes, mantendo, assim, viva a cultura polonesa, sendo esta repassada de geração para geração (KOKUSZKA, 2001).

Baumann (2013) apresenta o termo "polonesidade" para explicitar a cristalização cultural dos imigrantes poloneses, sendo esta caracterizada como a materialização das características polonesas que são levadas com seus emigrantes para os demais países do mundo. Para o autor, este traço cultural é de crucial simbolismo para que se mantenha viva a tradição originária deste povo.

A polono-brasilidade apresenta-se como a 
mescla cultural entre os imigrantes poloneses e os seus descendentes que hoje residem em diferentes regiões do Rio Grande do Sul e do Brasil. Esta polono-brasilidade consiste em atributos herdados dos imigrantes - sendo estes representados por diversos códigos culturais - que hoje se mesclam com a cultura brasileira e sobretudo, com a cultura gaúcha. Para Poplavski (2017, p. 48), "dentro do 'cadinho' étnico e cultural diversificado, característica do Brasil e do Rio Grande do Sul de hoje, temos o elemento polonês como um dos mais expressivos e influentes".

Desta forma, a cultura polonesa é parte das diversas etnias colonizadoras do Rio Grande do Sul, constituindo uma das tantas figuras que conformam a figura do gaúcho, seu tradicionalismo perpetuado, bem como sua mutabilidade sob as influências externas.

A identidade polonesa mantém-se ao longo das décadas através de diversos costumes passados de geração para geração. Segundo Delong e Dorotea (2014), esta identidade é construída ao longo da vida, nas diferentes interações e práticas sociais. Não é um fenômeno individual, mas social, onde a identidade é o que nos faz ser reconhecidos como um certo tipo de pessoa em um determinado contexto.

\section{RELIGIOSIDADE}

A religiosidade se apresenta como uma das principais difusoras da cultura polonesa e um significativo código cultural. Provindos de uma nação onde a religião católica era predominante, os imigrantes procuraram manter os ritos católicos nas novas terras (GRITTI, 2004), a partir da construção da igreja e da devoção a Nossa Senhora do Monte Claro (Matka Boska Częstochowska).

Para Krupinski (1990), as principais tradições polonesas se mantêm, em grande parte, ligadas diretamente a vida religiosa na comunidade, sendo que ela é composta não apenas pelos ritos religiosos, mas também através de suas inter-relações, dadas no convívio que é construído pelos membros.

A materialização desta fé e devoção dos poloneses se concretizaram já na chegada destes imigrantes onde hoje se localiza o município de Áurea. Antes mesmo de se inserirem nas tarefas de abertura das estradas, eles se empenharam em construir uma igreja para que pudessem exercer a religião que traziam desde a terra natal.

Diversas edificações foram construídas ao longo das décadas, até a finalização da igreja atual, que foi inaugurada no ano de 1960, sendo seu projeto e execução dirigidos por profissionais provindos do país europeu, visando à construção de uma matriz que carregasse as características dos modelos religiosos da Polônia (Figura 1).

Observa-se no altar da igreja as diferentes representações da religiosidade sob a influência polonesa, sendo esta manifestada pela imagem de Karol Józef Wojtyta (Papa João Paulo II), e a imagem de Matka Boska Częstochowska (Nossa Senhora do Monte Claro), considerada a "Padroeira da Polônia". 
Figura 1 - Altar da Igreja - Matka Boska Częstochowska.

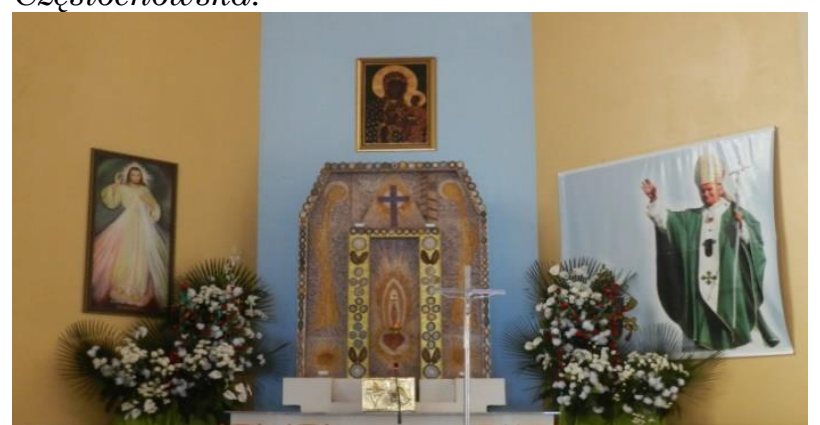

Fonte: Autor, 2017.

Os ritos das principais festividades religiosas também carregam traços da Polônia. O Natal e a Páscoa, também comemorados com devoção pelos adeptos brasileiros da religião católica, são celebrados com fortes traços de como eram realizados no país europeu. No domingo de Páscoa, os alimentos são levados até a igreja, onde são benzidos, para somente depois serem consumidos pelas famílias. A vigília de Natal é realizada a partir da partilha do pão (optatek). Para os descendetes dos imigrantes poloneses, os votos natalinos contidos no opłatek são “a expressão da fraternidade sincera, humana e familiar". Findadas as celebrações, todos se dirigem à igreja para participar da Missa do Galo (pasterka).

A religiosidade foi também um importante difusor da língua polonesa entre os imigrantes que passaram a residir em Áurea. Inicialmente, o letramento litúrgico se dava unicamente em língua polonesa, com padres imigrantes que eram enviados às paróquias das colônias polonesas no Brasil, para que se mantivessem os costumes e hábitos linguísticos da pátria polonesa. Posteriormente, com a finalidade de inserção cultural com as demais comunidades, se passou a ensinar também na língua portuguesa, sendo o ensino realizado na parte da manhã na língua polonesa e, pela parte da tarde, na língua portuguesa. Desta forma, o letramento litúrgico se insere como um importante fator de identidade destes imigrantes.

Assim, a religiosidade não somente foi importante para o apoio espiritual dos primeiros imigrantes para suportarem as condições adversas da colonização, como também permitiu a coesão identitária do grupo que permanece nos dias de hoje, embora com novos desafios para a sua permanência.

\section{LÍNGUA E DIALETO}

A língua e o dialeto se constituem também como um código cultural de suma importância, que se mantém vivo no cotidiano e nas escolas do município, que além da língua portuguesa, também ensinam a língua polonesa. Kokuszka (2001) se refere a este fato como uma interação entre a escola e a sociedade onde ela está inserida, sendo que o ensino deve ser voltado às necessidades sociais e à integração entre ambas, de forma conjunta.

No período inicial da colonização polonesa, os imigrantes que passaram a colonizar o município de Áurea dialogavam entre si apenas no idioma polonês, uma vez que não possuíam conhecimento e/ou domínio da língua portuguesa. Essa interação e aprendizagem ocorreu inicialmente em forma de dialeto e na comunicação mista entre as 
duas linguagens, sendo este parte de um lento processo de inserção, dado que as duas linguagens possuem profundas diferenças em suas raízes. Essa prática de mantenimento da língua polonesa na comunidade era incentivada principalmente pelos padres poloneses que vinham da Polônia com o intuito de manterem vivas as tradições linguísticas e religiosas do país europeu.

É preciso destacar que existem diferenças entre língua, idioma e dialeto. Língua, tal como a portuguesa e a polonesa, é um sistema formado por regras e valores presentes na mente dos falantes de uma comunidade linguística e aprendido graças aos inúmeros atos de fala com os quais eles têm contato. Por sua vez, idioma é um termo referente à língua usado para identificar uma nação em relação às demais e está relacionado à existência de um estado político. Já dialeto é a designação para variedades linguísticas, que podem ser regionais ou sociais.

Observa-se que atualmente grande parte da população ainda se comunica oralmente a partir do dialeto polonês na cidade de Áurea, porém não há um amplo domínio no que se refere a parte escrita. Além da baixa escolaridade de alguns habitantes, isso se explica pelo fato de que a leitura e a escrita não são praticadas, dado que, na maioria dos casos, aprende-se a língua polonesa no âmbito familiar, a partir de diálogos de temas variados do dia a dia, referentes principalmente ao trabalho no campo.

A língua polonesa, ainda que praticada nas esferas familiares e religiosas, tende a gradativamente ter menos alcance ao longo das gerações. Hoje, este dialeto se restringe a poucos canais de comunicação.

A língua e o dialeto polonês são um importante código cultural, que se imprime principalmente no domínio imaterial, e que reverbera em toda a cultura polonesa entre os descendentes de imigrantes. Como símbolo de um povo, a língua é o primeiro traço de territorialização, e é o que ainda mantém, em maior grau, a proximidade destes habitantes com o país europeu.

\section{DANÇA, MÚSICA, ARTE E TRAJES TÍPICOS}

Outro importante código cultural é o folclore polonês, representado através de danças e canções populares, bem como em suas manifestações artísticas e trajes típicos.

Como materialização da cultura através da música e da dança, existe atualmente no município o grupo folclórico Auresóvia (denominação referente à junção entre o nome da cidade e de Varsóvia, capital da Polônia) que interpreta danças e diferentes representações artísticas polonesas. Fundado em 1988, a partir do incentivo e da organização de religiosos ligados à Paróquia de Nossa Senhora do Monte Claro, o grupo apresenta danças polonesas com características regionais, onde se observam vestimentas, ritmos e traços que são marcantes para que se compreenda suas origens e representações.

As danças apresentadas pelo grupo são divididas entre os elencos a partir de sua faixa 
etária, de modo que se formam grupos mirins, juvenis, adultos e másters. As principais danças são: Kokotek, dança da região da Silésia, apresentada pelo elenco mirim; Kaszuby, sendo esta caracterizada como uma dança regional do norte da Polônia, apresentada pelo elenco juvenil; Krakowiak, sendo esta uma dança nacional, das mais antigas e representativas para os poloneses, onde os passos imitam os movimentos de galope dos cavalos, apresentada pelo elenco adulto; e Trojak, dança popular da Silésia, dançada por um homem e duas mulheres, apresentada pelo elenco máster.

O que se destaca deste código cultural é a sua confecção, já que os trajes são produzidos pelos membros da comunidade, carregando, portanto, características únicas de produção e representando as regionalidades da Polônia. Esta característica faz com que as vestimentas polonesas utilizadas no município sejam, de certa forma, produto da polonidade vivenciada e perpetuada pelos descendentes de imigrantes poloneses, carregando e construindo traços que se destacam de outras regiões e colônias de povoamento polonesas.

A música tradicional polonesa se perpetua em Áurea na forma das festividades típicas, por meio da ligação que carrega com o país de origem dos imigrantes, bem como pela sua representatividade nas danças folclóricas, através de apresentações culturais que se caracterizam pelas vestimentas típicas e estilos regionais marcantes.

A arte, em suas diferentes formas e manifestações, se configura como uma das principais difusoras da cultura polonesa entre seus descendentes. Para Baumann (2013), a missão da arte é salvar-nos do esquecimento do ser. Desta forma, as representações artísticas polonesas são reflexos de seus diferentes períodos ao longo da história, sendo esta traçada e caracterizada principalmente pelos cultos religiosos, através das diversas colorações nas imagens, da representação dos períodos de opressão vividas pelas ocupações, entre outros períodos que são de fundamental entendimento para que se interprete tais construções.

Dentre a enorme variedade e grande riqueza da arte popular polonesa, o wycinanka, uma antiga arte popular polonesa feita com recortes de papeis e muitas cores, ocupa lugar de destaque como arte decorativa, fruto da manifestação do temperamento artístico do povo polonês, sempre caracterizado por ser uma arte representada pela união de diversas cores.

A tradição dos ovos pintados na celebração da Páscoa mantém-se viva na tradição dos imigrantes poloneses, ligados diretamente aos ritos religiosos. Para eles, o ovo é tido como um símbolo de vida e procriação, sendo, para muitos cristãos, um símbolo da ressurreição.

Estas formas de representação a partir da arte, bem como o conhecimento da história e o valor da representação que se carrega com essas manifestações artísticas, são traços culturais que se caracterizam também por serem de suma importância para a cultura polonesa entre os descendentes de imigrantes. 


\section{ARQUITETURA}

A narrativa sobre a arquitetura polonesa é complexa quanto a trajetória política desta parte da Europa. As fronteiras da Polônia foram modificadas diversas vezes, as partilhas e a perda da independência, a destruição durante os tempos de guerra e, finalmente, os fundos europeus que estimulam o mercado de construção civil são fatores que contribuem para a imagem da arquitetura polonesa. É versátil, surpreendente, moderna, mas também, com frequência, muito tradicional, caracterizada principalmente por elementos que remontam os reflexos de estruturas voltadas para o abrigo durante o inverno.

Uma das principais características das construções polonesas são as colorações de suas fachadas, representadas por cores quentes, e, em seu interior, uma estrutura que beira a simplicidade, reflexo da histórica condição econômica do país, onde sua população se via limitada no que tange à aquisição de bens (Figura 2).

Figura 2 - Arquitetura polonesa em Áurea/RS

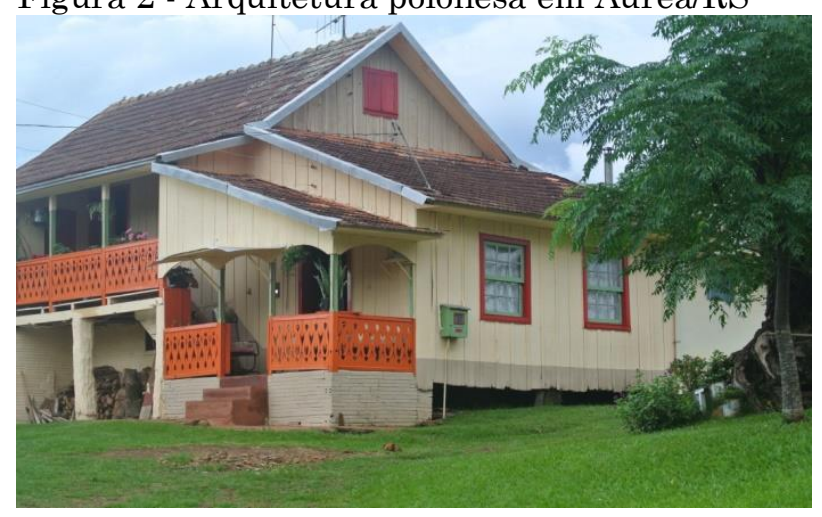

Fonte: Autor, 2017.

Observam-se algumas características da arquitetura polonesa que ainda podem ser encontradas no município de Áurea. Tal representação se caracteriza pela coloração quente, madeiras trabalhadas com adornos e contornos artísticos, bem como encaixes de madeira com pouca ou quase nenhuma utilização de hastes de metal.

A Igreja da Paróquia de Nossa Senhora de Monte Claro é um exemplo da difusão da arquitetura característica polonesa. A igreja em questão é de arquitetura influenciada pelo estilo arquitetônico das igrejas polonesas. A simplicidade ornamental, tanto da sua fachada quanto do seu interior, e devoção materializada por poucos adornos religiosos são características simplórias da arquitetura polonesa.

$\mathrm{O}$ estilo arquitetônico polonês ainda pode ser observado em algumas residências e edificações do município de Áurea, configurando-se, assim, como um importante código cultural. Ressalta-se que as casas ao estilo polonês diferenciam-se das originais encontradas na Polônia, devido, principalmente, as condições climáticas encontradas no Brasil.

O que se observa, com base na análise documental histórica, é que a influência arquitetônica concretizada pelos imigrantes se deu na modelagem das moradias, realizadas com madeira, a partir do encaixe, isto é, sem o auxílio de pregos e demais materiais. Vale ressaltar que esta também pode ser considerada uma característica das construções alemãs e de outros países europeus, demonstrando, desta forma, a 
influência externa perpassada na arquitetura polonesa.

Este estilo de construção é caracterizado por Wenczenovicz (2010). A autora expõe que, no momento da instalação no lote colonial, a edificação da residência estava entre as mais importantes para o início do empreendimento. Em geral, foi o imigrante que edificou sua casa, utilizando-se de material encontrado na propriedade: barro, madeira, palha e pedra. Os pregos quase não foram utilizados na arquitetura polonesa, apesar de eventualmente serem utilizados pelos imigrantes alemães e italianos. Os poloneses utilizaram, sobretudo, o sistema de encaixes de madeira - blocause -, usado na Polônia durante vários séculos, principalmente na área rural.

Em Áurea, a arquitetura polonesa é representada por poucas residências e edificações que mantêm esta estrutura característica. O mesmo se aplica a mobília das residências, sendo que grande parte desta herança dos imigrantes se encontra exposta em museus. O que se observa é que as estruturas de galpões e áreas destinadas às atividades agrícolas e à criação de animais ainda existem em algumas propriedades, porém estão se degradando ao longo dos tempos.

\section{CULINÁRIA}

A cultura de um território é expressa de diferentes formas, entre elas através da culinária. A culinária é o conjunto de receitas, técnicas e regras compartilhado coletivamente. Ela "contém e expressa a cultura de quem a pratica, é depositária de tradições e das identidades dos grupos. Constitui, assim, um extraordinário veículo de autorrepresentação e de comunicação intercultural" (MONTANARI, 2009, p. 11), além de deixar transparecer as preferências coletivas e refletir estruturas da sociedade (CLAVAL, 2014).

A gastronomia típica polonesa configurase também como um importante código cultural de Áurea, representada por diferentes pratos e bebidas, a culinária polonesa é passada de geração para geração.

A czarnina é o prato mais difundido da culinária polonesa entre seus descendentes, juntamente com o pierogi, sendo que, muitas vezes, um acompanha o outro nas refeições. A czarnina consiste em uma sopa produzida com carne de pato, mergulhado em seu sangue, que tornou-se popular na Polônia e Lituânia, no século XVII, e até hoje é um prato que faz parte do cotidiano alimentar dos poloneses. Já o pierogi é uma espécie de pastel cozido, originário da Polônia e oeste da Ucrânia, onde é chamado pyrohy.

O Ognizco (Figura 3) também é uma representação que ainda pode ser encontrada em Áurea nos dias atuais. O rito se caracteriza por uma fogueira acesa com fogo de chão, onde se assa linguiça, individualmente, com um pedaço de madeira rudimentar, normalmente uma taquara artesanal. Etimologicamente, ognizco significa "fogo/fogueira", e é realizado como forma de representação da união entre as comemorações de festas juninas com as 
tradições polonesas, tendo como objetivo relembrar os costumes dos antigos pastores da Polônia, que se alimentavam e festejavam ao redor do fogo durante o rigoroso inverno europeu.

Figura 3-Ognizco.

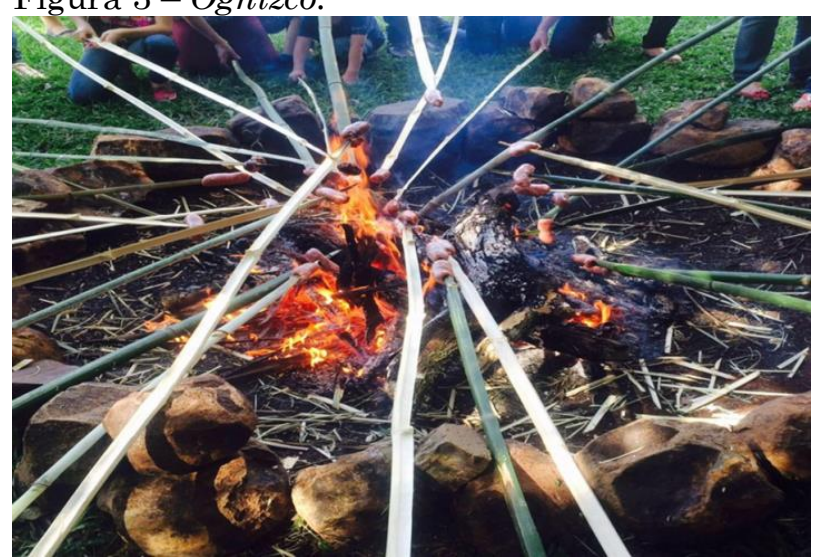

Fonte: Autor, 2017.

A culinária típica polonesa mantém-se como um forte laço cultural com o país europeu, uma vez que se perpetua entre as famílias em suas refeições diárias. Esta culinária se caracteriza também pela sua mutabilidade e adesão de novos ingredientes provenientes do Brasil, tais como a erva-mate, o churrasco e demais hábitos e tradições gastronômicas incorporadas principalmente a partir da influência de indígenas e gaúchos.

\section{CONSIDERAÇÕES FINAIS}

Quase um século após a chegada dos primeiros colonos poloneses, Áurea continua sendo uma localidade predominantemente ligada à origem étnica dos moradores e, ainda hoje, é identificada como "polonesa". Esta polonidade, vivenciada principalmente pelas gerações mais próximas aos imigrantes do início do século $\mathrm{XX}$, ainda se perpetua nos diferentes códigos culturais que estão presentes no cotidiano de Áurea, como nos ritos religiosos, no dialeto polonês, nos campos das artes, da arquitetura, da música e das danças, bem como na culinária.

A colonização de Áurea significou para os imigrantes poloneses uma questão política de autonomia, onde o território está intimamente ligado à perpetuação de sua cultura. Esta realidade se conserva nos dias atuais, já que o município de Áurea se configura como uma área específica, no norte do Rio Grande do Sul, que mantém as tradições polonesas preservadas.

A polonidade é expressa como a cultura perpetuada pelos descendentes de imigrantes poloneses e se materializa como uma cultura híbrida de hábitos ligados diretamente aos imigrantes e aos costumes e tradições brasileiras, representadas pelos gaúchos e pelos indígenas. Não há como isolar a cultura polonesa que se mantém atualmente no município, sem que se compreenda suas influências externas adquiridas após o período migratório.

Desta forma, percebe-se que a cultura polonesa, representada por seus diferentes códigos culturais, ainda é significativa na organização espacial do município de Áurea, fazendo com que ele possua o título de "Capital Polonesa dos Brasileiros", evidenciando o revigoramento das identidades polonesas locais através de seus símbolos e códigos culturais, bem como através dos diferentes 
costumes e tradições que se mantêm.

Os códigos culturais são manifestações que cumprem um papel de favorecimento da identidade do grupo. O realce dessas questões como elementos formadores de identidade cultural demonstra a importância de tais símbolos para os estudos geográficos dos grupos que possuem fortes vínculos socioterritoriais ou daqueles que participam de eventos migratórios.

\section{AGRADECIMENTOS}

Os autores agradecem a Universidade Federal de Santa Maria, por meio do Programa de PósGraduação em Geografia (PPGGEO) pelas contribuições para a realização da presente pesquisa. Este trabalho foi realizado com apoio da Coordenação de Aperfeiçoamento de Pessoal de Nível Superior - Brasil (CAPES) Código de Financiamento 001.

\section{REFERÊNCIAS}

ALMEIDA, M. G. Fronteiras, territórios e territorialidades. Revista da ANPEGE. Fortaleza, ano 2, n. 2, 2005, p. 103-114.

BAUMANN, Z. A cultura no mundo líquido moderno. Rio de Janeiro: Zahar, 2013.

BRUM NETO, H. Regiões culturais: a construção de identidades culturais no Rio Grande do Sul e sua manifestação na paisagem gaúcha. 2007. 319 p. Dissertação (Mestrado em Geografia) - Santa Maria: Universidade Federal de Santa Maria. 2007.

CLAVAL, P. A geografia cultural. Ed. UFSC. Florianópolis, 2014.

CORRÊA, R. L. Formas simbólicas e espaço: algumas considerações. GEOgraphia, Revista da Pós-Graduação em geografia da UFF. 2012, p. 99 - 111.

DECOL, R. D. Uma história oculta: a imigração dos países da Europa do CentroLeste para o Brasil. In: Anais do XII Encontro Nacional de Estudos Populacionais, 2000,
Campinas. Campinas: PUC Campinas, 2000.

DELONG, S. R.; DOROTEA, F. K. Domínios de linguagem. Universidade Federal de Uberlândia. V. 8, n. 3 (ago./dez. 2014) - ISSN 1980-5799.

GARDOLINSKI, E. Imigração e colonização polonesa. In: BECKER, Klaus (org.) Enciclopédia Rio-grandense. v. 5. Canoas: Regional, 1956. p. 1-104.

GRITTI, I. R. Imigração e colonização polonesa no Rio Grande do Sul: a emergência do preconceito. Porto Alegre: Martins Livreiro, 2004.

HAESBAERT, R. Identidades Territoriais. In: CORREAA, R. L.; ROSENDAHL, Z. (Org.). Manifestações da cultura no espaço. Rio de Janeiro: EdUERJ, 1999. p. 169-190.

INSTITUTO BRASILEIRO DE GEOGRAFIA E ESTATÍSTICA. Cidades. < https://cidades.ibge.gov.br/brasil/rs/aurea/pan orama>. Acesso em: 03 de novembro de 2019.

KOKUSZKA, P. M. Nos rastros dos imigrantes poloneses = Sladami Polskich Imigrantów. 2 ed. Curitiba, PR: Arins, 2001.

KRUPINSKI, R. Paróquia Nossa Senhora do Monte Carlo, 1915-1990. Passo Fundo: Ed. UPF. 1990.

MONTANARI, M. O mundo na cozinha. São Paulo: Estação Liberdade/SESC, 2009.

PICCIN, E. O código cultural religião como uma das manifestações da identidade cultural da quarta colônia de imigração Italiana/RS. Dissertação (Mestrado) - Santa Maria: Universidade Federal de Santa Maria. 2009.

POPLAVSKI, C. Milagres. Erechim: Editora GRAFFOLUZ, 2017.

RAFFESTIN, C. Por uma Geografia do Poder. São Paulo (SP): Ática, 1993.

SOUSA, M. J. L. O território: sobre espaço e poder, autonomia e desenvolvimento. In: Castro Iná et al. (Org.). Geografia: conceitos e temas. Rio de Janeiro: Bertrand Brasil, 1995.

STAWINSKI, A. V. Primórdios da imigração polonesa no Rio Grande do Sul (1875 1975). Porto Alegre, Escola Superior de Teologia São Lourenço de Brindes; Caxias do Sul, UCS. 1976.

WENCZENOVICZ, T. J. Montanhas que furam as nuvens! Imigração polonesa em Áurea - RS (1910 - 1945). Dissertação (Mestrado) - Passo Fundo: Universidade de Passo Fundo, 2002.

Pequeninos poloneses: cotidiano das crianças polonesas (1920-1960). Xanxerê, Ed. News Print, 2010. 